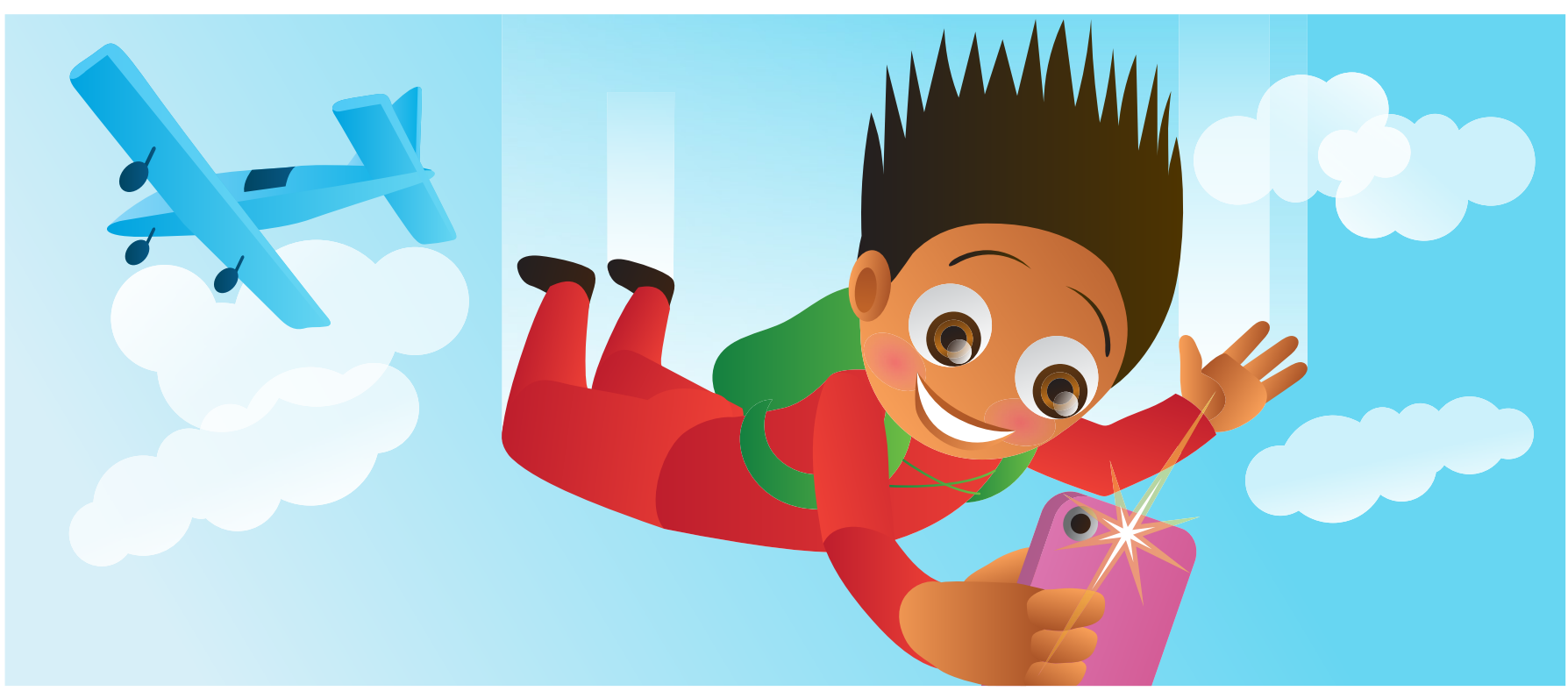

\title{
I WANT IT NOW! THE NEUROSCIENCE OF
}

\section{TEENAGE IMPULSIVITY}

\section{Christina Leuker and Wouter van den Bos*}

Max Planck Institute for Human Development, Berlin, Germany

REVIEWED BY:

FRANCISCO

LINCOLN

13 YEARS OLD
What would you rather do on a hot summer day? Go to football practice or have ice cream by the pool? The pool might be much more fun than going to any sports practice, so it may seem to be an easy choice. However, if you miss practice often, your coach might not line you up at the next match, and you will not improve overall. In the light of these future consequences, attending practice might not look so bad after all. Yet, research shows that teenagers, more often than people of any other age, tend to follow their short-term impulses rather than pursuing long-term goals. Why do teenagers have so much difficulty controlling their impulses? And how does this get better as you get older? We studied the developing brain and found that controlling impulses depends on at least two different brain areas. As you grow older, connections between these two brain areas get stronger: this helps you think about the future consequences of your actions, be less impulsive, and (maybe) also make better decisions.

\section{WHAT IS SPECIAL ABOUT BEING A TEENAGER?}

In your teenage years, your parents usually start to allow you to make more and more decisions yourself. You start picking hobbies, the friends 


\section{ADOLESCENCE}

The ages between puberty and adulthood, approximately $10-20$ years old.

\section{IMPULSIVITY}

Doing things or tending to do things suddenly and without careful thought.

\section{IMPATIENCE}

Having a hard time waiting for something in the future. you hang out with, and what to do after school. Then, at some point, you become independent from your parents [1]. This growing-up phase is called adolescence. It starts with puberty and ends whenever we consider someone an adult (spanning ages 10-20 years, roughly). It is a very special phase because adolescents behave differently than younger kids and adults in many ways.

For instance, teenagers are known for their impulsive behavior. That is, they seem to do many things without thinking too much about the consequences. In some ways, impulsivity can actually be a good thing: imagine if you only did things for which you knew the consequences exactly! This would not only be mind-numbingly boring but also make it impossible to learn anything new. Going into a swimming pool for the first time might be scary, but then again, you cannot learn swimming without going into the water.

Teenagers, but not young children, are allowed to make their own decisions and they spend less time under the direct supervision of their parents. This gives teenagers a lot of opportunity to learn new things, but because making the right decisions is not always easy, this freedom may also lead to mistakes. Sometimes these mistakes, driven by impulsive behavior, can lead to serious negative outcomes. For instance, teenagers end up in emergency rooms after being involved in accidents more often than adults or children [2].

So, why are teenagers so impulsive? Understanding this impulsivity is important for parents (who need to let their kids have their own experiences but do not want them to be involved in accidents), teenagers (who want to have fun but also need to think about future consequences), and society (which needs to make laws about the appropriate age requirements for risky activities, such as drinking alcohol, smoking, or driving a car). In an effort to understand how teenagers make very impulsive or less impulsive decisions, we studied the developing brain.

\section{A SMALL REWARD NOW OR A BIG ONE LATER?}

We investigated one particular aspect of impulsivity, namely, impatience. Impatience describes the hard time you have when you need to delay something to a later point in time, but you would really like to have it now (for example, going to the pool after finishing sports practice). Psychologists have studied impatience using a famous "marshmallow test." This is how it works: imagine that a girl named Julia (5 years old) is given a marshmallow on a plate in front of her. Before the experimenter leaves the room, she explains that Julia can either eat the marshmallow immediately or she can wait until the experimenter comes back. If the original marshmallow is still there, Julia will get an additional marshmallow. Some children will eat the marshmallow 
immediately, while others will wait. However, waiting is not easy! (And it is funny to watch: you can see this in action if you go to YouTube and type in "The Marshmallow Test"). Of course, as we get older, we do get a lot better at waiting for rewards. Most adults do not have much trouble waiting for the marshmallow; however, teenagers are often still very impulsive. Why is waiting usually so hard for children and teenagers but easier for adults? There are several reasons we can think of.

One reason is that, as you get closer to being an adult, you get better at controlling your attention. Most kids have difficulty controlling what they pay attention to, but some kids can already do it! Walter Michel, who conducted the first marshmallow test, found that kids who were able to wait until the second marshmallow were very successful in taking their attention off of the marshmallow. For instance, some kids simply turned their chair around, so that they were not looking at the candy. Other kids used a different strategy, one that is more difficult to see, that is, thinking about something else. For instance, they might imagine what it is like to have two marshmallows, or that the marshmallow in front of them is actually fake and made out of stone. This ability to direct our attention where we want it to go usually gets easier as we get older and become adults.

Another reason that teenagers are impulsive and have difficulty waiting for long-term rewards is that their brains appear to be very sensitive to immediate rewards - teenagers tend to really like them! In the early teenage years, the part of the brain that processes emotions undergoes large changes, making immediate rewards seem extra good to teenagers $[1,3]$. As a result, the immediate reward (e.g., eating the marshmallow now) may appear much more rewarding for the adolescent than for the adult, and they may be less willing to wait for the long-term reward.

At this stage, we are not really sure what is going on in the teenage mind. Over time, (most) teenagers seem to get better at waiting. But, why is this the case? To get a better idea of what is going on, it may help to take a look at the brain as it matures from adolescence to adulthood.

\section{STUDYING IMPATIENCE IN THE LAB}

To study how the brain is changing when you are a teenager, we had participants between the ages of 8 and 25 years old take part in a lab experiment. In our experiment, every participant had to choose between two different amounts of money, one that he/she would get very soon or one he/she had to wait a bit longer to get (Figure 1A). For example, would you prefer to get $\$ 10$ now or $\$ 27$ in 28 days? (What would you prefer? You can answer this question for yourself.) Similar to the marshmallow experiment, to get more money the 


\section{FIGURE}

A. These are two examples of the choices in our study of what is going on in the teenage brain when teenagers have to choose between immediate and delayed rewards. Participants always had to decide between a smaller amount of money that they would get sooner or a larger amount of money that they would have to wait longer for. B. All participants made choices in a brain scanner, so that brain activity could be recorded. The options were shown on a computer screen that was visible from the scanner.

\section{MAGNETIC}

\section{RESONANCE}

IMAGING (MRI)

Stands for Magnetic resonance imaging and refers to a very strong magnetic brain scanner used to image and record activity in the brain.

\section{STRIATUM}

A brain area that keeps track of how much you like something (among many, many other tasks).

\section{FIGURE 2}

A. Imagine, for this figure that a person is standing in front of you looking left and his brain is cut in the middle, from front to back. This gives you an "inside view" of the brain, revealing many structures that we would not observe at the brain's surface alone. You can see that the striatum is located somewhere in the middle (in green). B. This shows you a 3D brain. The dIPFC is located in the front (in blue).
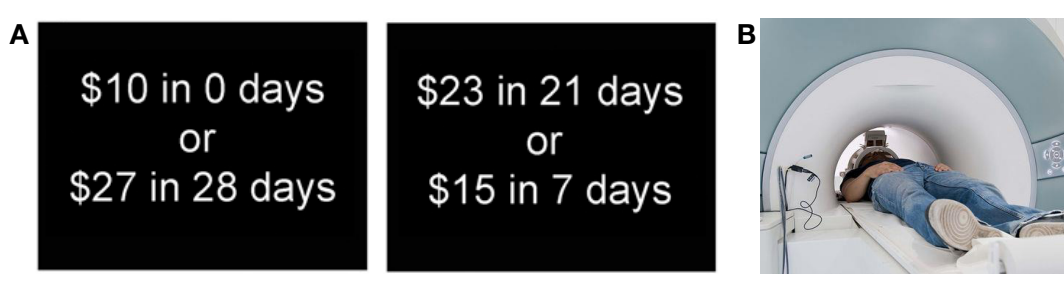

FIGURE 1

participants would have to wait longer. In this experiment, we used money instead of marshmallows because this is much more practical; you cannot eat marshmallows in the brain scanner! Also, not everybody likes marshmallows but almost everybody likes money! As we expected, we found that the younger participants were less willing to wait for the larger amount of money than were the older participants.

Although the participants were making the choices, they were in lying in a scanner called a magnetic resonance imaging (MRI) scanner, like the one you see in Figure 1B. With the MRI scanner, we measured two things such as (1) the levels of activity in different parts of the brain and (2) the structure of the brain.

\section{A LOOK INSIDE THE BRAIN}

From what we know so far, two brain areas are important when people make decisions about which rewards they want to receive. The first area is the one that encodes all kinds of reward information. It accounts for how much you like playing video games, how much you like being a football player (or some other sport, or playing an instrument), and how much you like watching TV or having an ice cream by the pool. This brain area is called the striatum (pronounced strai-ay-tuhm). The second important brain area is involved in keeping track of your long-term goals (like becoming a famous football player).

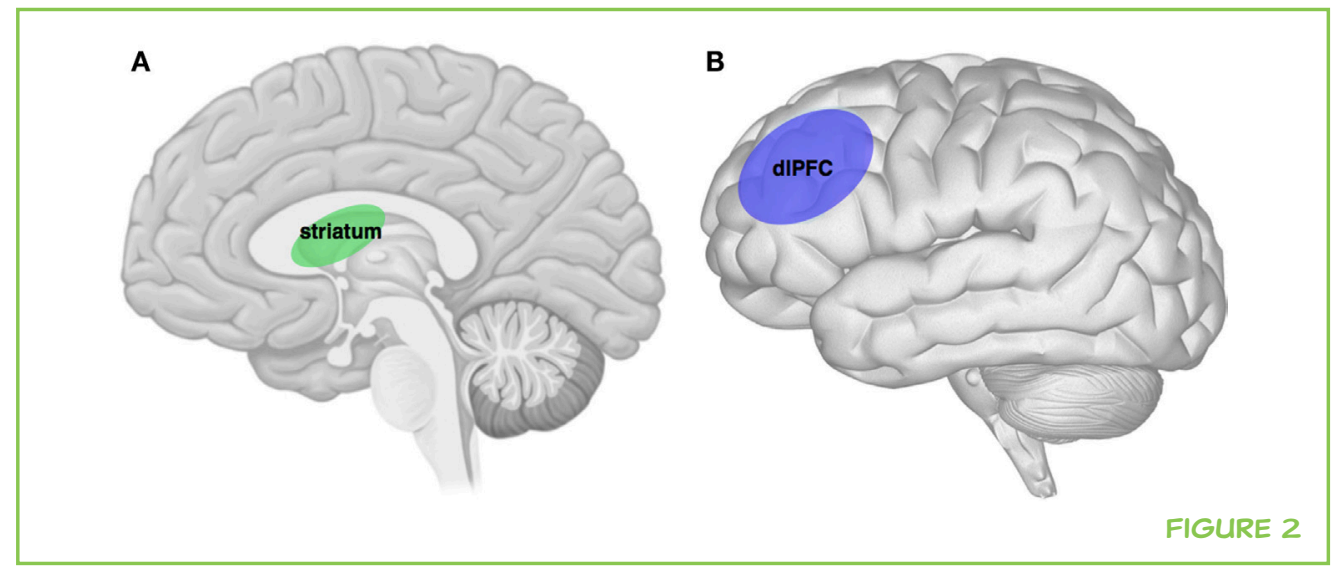


DORSOLATERAL PREFRONTAL CORTEX (DLPFC)

A brain area that keeps track of your long-term goals (among many, many other tasks).
FIGURE 3

A1,B1. As you get older, connections between the striatum and the dIPFC become stronger. Stronger connections allow for more information to flow from the dIPFC to the striatum. A2,B2. You can compare this to adding more lanes to a road. The brain's gained ability to let more information flow between areas can be compared with more cars being able to drive on a road.

These goals are encoded in a brain area called the dorsolateral prefrontal cortex (dlPFC). One way of thinking about the dlPFC is as a parent who is telling you to do what is good for your future self ("you will thank me later"), and in a way works as a "future simulator." You can see where the striatum and dlPFC are located in Figure 2.

The striatum and the dlPFC are also connected via pathways of brain cells called neuronal pathways. You can think of the connection as a road that is used to pass messages from one brain region to the other. Through the neuronal connections, the dlPFC is able to "talk" with the striatum and tell it what the future benefits of your choices are. This "talking" is important because most decisions in life are not clearly good or clearly bad - we always have to weigh different parts of a decision. (How much are you willing to give up today for a bigger reward tomorrow? Maybe eating two marshmallows in a row later does not even taste as good as the first one now.) In our experiment, we examined this "talk" between the striatum and dlPFC in more detail.

\section{WHAT DID WE FIND?}

First, we looked at the strength of the connections between the dlPFC and the striatum. Our results showed that stronger connections between the dlPFC and the striatum are created as you get older (indicated by the yellow arrow getting bigger in Figure 3). This can be compared with widening a single-lane road into a multi-lane highway.

Next, we measured brain activity in the dlPFC and in the striatum while participants made their choices. When the activity in the two brain regions is very similar, increasing and decreasing at the same time, we assume that there is a lot of communication between these two regions. We found that, as

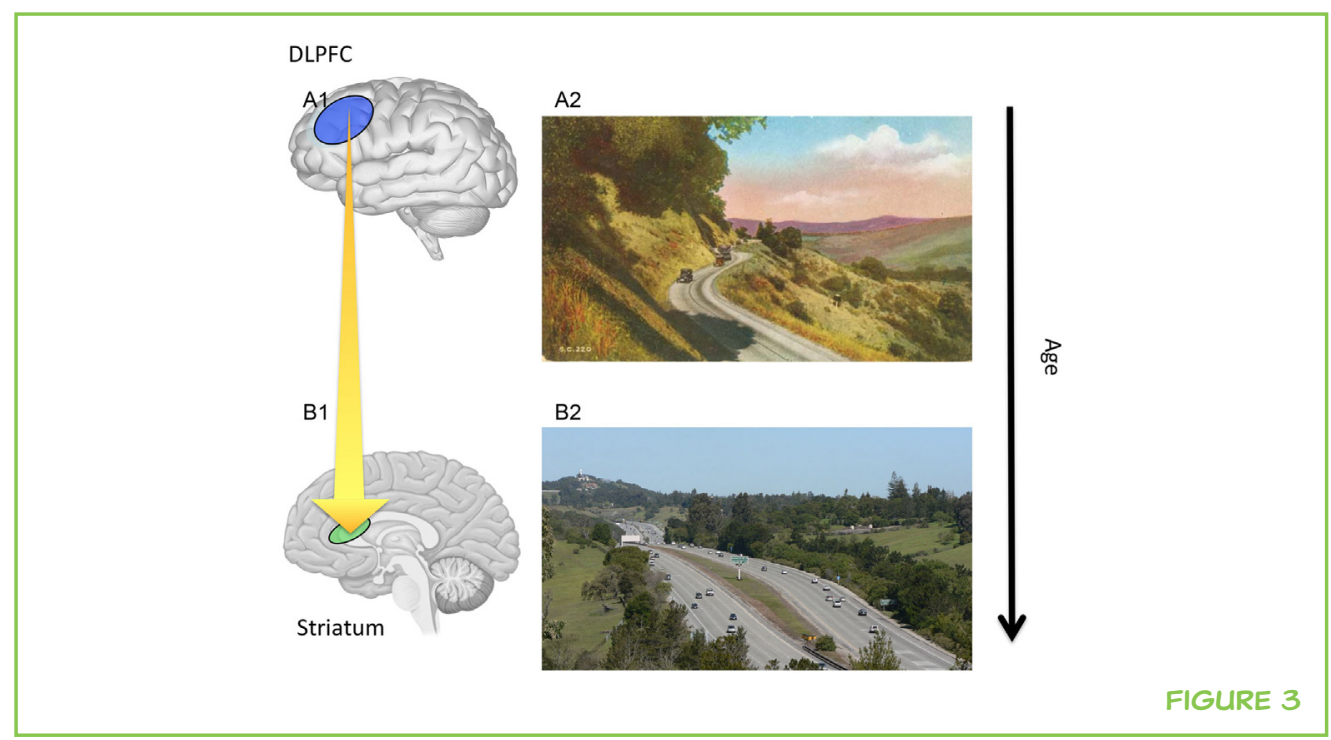


you get older, there is increased communication between the dlPFC and the striatum, which could be compared with an increased number of cars on the road (Figure 3). Most importantly, we found that the older participants whose brains had already "built" big highways between the dlPFC and the striatum were less impulsive. They preferred waiting for the larger amount of money rather than taking a smaller amount of money immediately. We think this happens because the dIPFC is now better able to tell the striatum about the benefits of waiting for the future reward [4].

\section{WHAT DOES THIS MEAN FOR YOU?}

Most of us enjoy chocolate, video games, and other fun things. And most of us would rather enjoy them now rather than later. But, people seem to differ in terms of how hard it is for them to wait for some of these good things to happen. In our brains, this is partly controlled by connections between the dlPFC and the striatum. The more the dlPFC and the striatum connect, the easier it is to wait for a reward. These connections are strengthened as you get older (Figure 3), which in the end makes you better at waiting a while for good things.

The construction of these faster roads in the brain is part of the normal processes of growing up, along with many other changes that happen in the body. But, you don not have to wait around until your brain starts making those connections. The cool thing is that you can train your brain and strengthen its connections! The brain is like a muscle: the more you use it, the easier those mental tasks will get over time. This applies to problems like the ones you see in math class or to playing board games (for more detail, see https://kids.frontiersin.org/article/10.3389/frym.2014.00005). But, it also applies to thinking about the future, which may still seem uncertain and blurry in your mind. You could, for example, improve your "reasoning-aboutthe-future" skills by thinking about specific future outcomes, like, "If I go to football practice it will help me to get lined up at the next match, and maybe I'll become a famous football player one day" [5]. Our best advice for participants in an experiment like ours would be to think really hard about what they could do with $\$ 27$ in 4 weeks compared with \$10 now. The \$27 could buy you almost three times as many toys, books, ice creams, or hot dogs than could $\$ 10$ now! The more you think about tomorrow the closer it looks!

\section{ORIGINAL SOURCE ARTICLE}

van den Bos, W., Rodriguez, C. A., Schweitzer, J. B., and McClure, S. M. 2015.

Adolescent impatience decreases with frontostriatal connectivity. Proc. Natl. Acad.

Sci. U.S.A. 112(29):E3765-74. doi:10.1073/pnas.1423095112. 


\section{REFERENCES}

1. Steinberg, L., and Chein, J. M. 2015. Multiple accounts of adolescent impulsivity. Proc. Natl. Acad. Sci. U.S.A. 112(29):8807-8. doi:10.1073/pnas.1509732112.

2. Eaton, D. K., Kann, L., Kinchen, S., Shanklin, S., Flint, K. H., Hawkins, J., et al. 2012. Youth risk behavior surveillance - United States, 2011. MMWR Surveill. Summ. 61(4):1-162.

3. Crone, E. A., and Dahl, R. E. 2012. Understanding adolescence as a period of social-affective engagement and goal flexibility. Nat. Rev. Neurosci. 13(9), 636-50. doi:10.1038/nrn3313.

4. Casey, B. J. 2015. Beyond simple models of self-control to circuit-based accounts of adolescent behavior. Annu. Rev. Psychol. 66:295-319. doi:10.1146/annurevpsych-010814-015156.

5. Peters, J., and Büchel, C. 2010. Episodic future thinking reduces reward delay discounting through an enhancement of prefrontal-mediotemporal interactions. Neuron 66(1):138-48. doi:10.1016/j.neuron.2010.03.026.

SUBMITTED: 27 August 2015; ACCEPTED: 24 May 2016;

PUBLISHED ONLINE: 07 June 2016.

EDITED BY: Jorge Moll, D'Or Institute for Research and Education (IDOR), Brazil

CITATION: Leuker C and van den Bos W (2016) I want it now! The Neuroscience of Teenage Impulsivity. Front. Young Minds 4:8. doi:10.3389/frym.2016.00008

CONFLICT OF INTEREST STATEMENT: The authors declare that the research was conducted in the absence of any commercial or financial relationships that could be construed as a potential conflict of interest.

COPYRIGHT @ 2016 Leuker and van den Bos. This is an open-access article distributed under the terms of the Creative Commons Attribution License (CC BY). The use, distribution and reproduction in other forums is permitted, provided the original author(s) or licensor are credited and that the original publication in this journal is cited, in accordance with accepted academic practice. No use, distribution or reproduction is permitted which does not comply with these terms.

\section{REVIEWED BY}

\section{FRANCISCO LINCOLN, 13 YEARS OLD}

I am 13 years old and I study in Rio de Janeiro, Brazil. I like to play soccer, read, and play the piano. I like studying math, science, and history. 


\section{AUTHORS}

\section{CHRISTINA LEUKER}

I am a PhD student at the Max Planck Institute for Human Development in Berlin, Germany. I am interested in how people make decisions. I am particularly interested in how the brain processes and integrates information about how much you like something and how likely you are to obtain it. In my spare time, I like doing sports, watching movies, making travel plans, hanging out with my friends, or going out for a burger. I spent some time in Texas during my studies, which is probably where this craving for American food originated.

\section{WOUTER VAN DEN BOS}

I am a research scientist at the Max Planck Institute in Berlin, and I am fascinated by the brain. I am specifically interested in how people make decisions, and how we can learn new things. I also study how the brain is changing when we get older, and how this changes how we make our decisions. In my research, I often ask the participants to make seemingly simple choices between two options. For instance, do you want some money now or a lot of money later. It is unbelievable how much you can learn about a person, and her brain, by asking such simple questions! *vandenbos@mpib-berlin.mpg.de 